\title{
ON THE PROBLEM OF MEASURING HAPPINESS
}

\author{
Sabine Hossenfelder*
}

NORDITA

Stockholm, Sweden

DOI: 10.7906/indecs.11.3.2

Received: 24 March 2013.

Regular article

Accepted: 28 June 2013.

\begin{abstract}
The question of how to measure and aggregate happiness is more than a century old. In recent years, its relevance has risen due to efforts to replace the GDP with an index more indicative of well-being, though such efforts are fraught with serious conceptual problems. After briefly recalling these problems, we suggest to address them by using, instead of the common ordinal utility, an alternative quantity that is maximized in economic transactions. This quantity counts the number of future possibilities a commodity opens. The big advantage of this approach is that, in principle, the number of possibilities is an objective measure which allows for intra- and interpersonal comparison. We lay out the framework of the model and then discuss its relevance for social welfare. While we do here not explicitly compute a measure supplementing the GDP, we sketch how this could be done in practice.
\end{abstract}

\section{KEY WORDS}

welfare function, alternatives to GDP

\section{CLASSIFICATION}

JEL: D04, D63

PACS: 89.65.Gh 


\section{PROBLEMS WITH THE UTILITY}

The utility function, the central ingredient to micro-economics, can be understood as an abstract measure for happiness. Originally this happiness was considered to be an, at least in principle, measurable quantity, but by the beginning of the $20^{\text {th }}$ century economists had convinced themselves happiness is fundamentally subjective and evades any absolute scaling. Quantifying one person's levels of happiness (intrapersonal), and comparing different persons' levels of happiness (interpersonal) should thus be avoided because such efforts are eventually meaningless. Fortunately, in 1906, Pareto showed that an ordering of preferences in 'good' and 'not so good' choices without an absolutely quantifiable measure is sufficient to reach an efficient equilibrium that maximizes happiness [1]. The absolute cardinal utility was thus replaced with the ordinal utility, and the concept of 'happiness' by that of 'choice' or 'preference.' Though in practice one often uses a particular quantification for the utility, this utility can be rescaled by an arbitrary monotonically increasing function.

While this shift from the cardinal to the ordinal utility has been advantageous by rendering it unnecessary to deal with subjective quantities, the utility is a problematic concept for several reasons.

The most basic problem is one of interpretation. With the use of the utility, the pursuit of happiness was conjectured to be the fundamental driving force of our economies. Selfevident as that might sound, putting aside for a moment our personal strive for happiness and looking at the evolution of civilizations, the idea that optimization of human happiness is what underlies the dynamics of this system does not make much sense. Being happy about ones actions is not the driver of evolution, neither the biological nor the economical one. It just happens that those who are happy about actions that also benefit the functionality of their metabolism have the advantage of desiring to do what helps them survive. Stil, what is fundamentally important for natural selection is survival, not happiness. The deceptiveness of happiness becomes clear when we consider drugs that stimulate the brain's reward system, promising happiness on the expenses of early death.

However, it is unnecessary to attach any particular interpretation to the utility. In models building upon it goods are utilized, but for no other purpose than to optimize the utility. One might thus postulate the utility as just some function that people happen to optimize in their decisions - it is thus fundamentally a concept empty of meaning. And while this point of view does away with the interpretational issue and is unproblematic from a mathematical perspective, it is experimentally unfalsifiable and thus scientifically problematic. Without an interpretation of the utility function independent of consumers actions, the question whether consumers do optimize their utility function can no longer be decided because it was postulated whatever they do is expression of that optimization already, and their behavior just reveals their preferences (certain properties of the function however can be subject to experiment).

Another fundamental problem is that with ordinal utilities different consumers cannot be compared since it cannot be decided whether one person's happiness exceeds that of another. Though this seems reasonable, the problem it causes becomes clear with the second welfare theorem. There are arbitrarily many states of our economy optimizing individual happiness that differ in the distribution of wealth. If a distribution of wealth is particularly uneven, one does intuitively think of trying to increase happiness by redistributing from the rich to the poor on the rationale that a rich man is less affected by the loss of $\$ 5$ than a poor man by its gain. Leaving aside the question how such a redistribution would be implemented, this process would decrease the happiness of the rich, but increase that of the poor. However, since the utility of different consumers cannot be compared and therefore cannot be 
aggregated, there is no way to find out whether the increase in happiness outweighs the decrease. There is thus no rationale for such an action based on the standard micro-economic theory. Only after defining a 'social welfare function' that essentially provides a weight for each consumer and thus allows to sum up or compare utilities becomes it possible to optimize 'social welfare.' Exactly, what is optimized then depends in general on the definition of 'social welfare' underlying the so-defined function. The utilitarian (Benthamite) welfare function for example treats all consumers the same irrespective of their circumstances of living.

In contrast to this, a Max-Min (Rawlsian) welfare function is maximized when the utility of those consumers who have the least is the greatest. There are further various other functions that one can chose, each of which offers a different notion of aggregation and of 'social welfare.' The use of the ordinal utility thus rendered the notion of 'social welfare' ambiguous and made it impossible to satisfactorily tackle many important problems in welfare economics.

\section{THE PURSUIT OF HAPPINESS}

One might then ponder the question whether neuroscientific advances will eventually allow us to indeed measure brain activity representing particular emotional states. Even if this became possible however, it is doubtful this would be meaningful for the economic purpose. Not only are there many ways of happiness and a direct response to stimulus is only one sort, this approach also raises the question what the relation between such brain activity and the economic relevance of the brain's owner should be. The idea that the ability of one's brain to reach high levels of electrical or chemical activity means some consumers are more, some less receptive to the unpleasantries of poverty is morally questionable and practically not very useful.

It thus remains the abstract notion of a preference map that is assumed to be existent but unknowable in principle, and only the used preferences are observable after they were acted upon. There are some few economists outside the mainstream who pursue the construction of a cardinal utility for either interpersonal or intrapersonal comparisons, based on neurological, psychological or statistical measures, see e.g. [2-4] and references therein. The more widely accepted approach of 'New Welfare Economics' measures people's satisfaction with social conditions by their willingness to pay, respectively accept, a monetary compensation for change, relaxing Pareto-efficiency to Kaldor-Hicks-efficiency. However, also in this case a cardinal measure for utility has to be used, thus the problem of aggregation remains.

The utility is thus an unsatisfactory basis for a model of our economy. One might instead take the analogy to biology seriously and attempt to explain our economy as a direct continuation of natural selection, an approach pursued in the context of sociobiology. And though such a reduction to more basic principles might theoretically be possible, our economic system exhibits such complex features and such a plethora of emerging social and cultural properties it seems a very challenging task to derive a useful model in this way.

The question of quantifying happiness recently raised to renewed importance. Within the last decade, it has become widely acknowledged that the GDP is a poor measure for a nation's well-being, one of the main reason being that it leaves aside the happiness of the nation's citizens. There are thus many suggestions to replace or adjust the GDP with ameasure that better represents the nation's success, among others the Happy Planet Index ${ }^{1}$, the Index of Sustainable Economic Welfare, or the Genuine Progress Indicator (for a review on these alternative measures, see [5]).

The awareness of the shortcomings of the GDP has meanwhile spread from academia to politics. In 2008, French President Nicolas Sarkozy asked U.S. economist Joseph Stiglitz, winner of the 2001 Nobel prize in Economics and a critic of free market economists, and 
Armatya Sen of India, who won the 1998 Nobel prize for work on developing countries, for advice on how to raise data more representative of his nation's status. The French government has since brought into life the Commission on the measurement of economic performance and social progress ${ }^{2}$ to pursue this aim. In November 2010, British PrimeMinister David Cameron announced his government's plans for measuring happiness [6], and it is not hard to predict that other nations will follow these examples.

Such efforts to improve the GDP and deviate competition for its optimization to a measure more indicative for well-being are overdue and welcome, but unfortunately do not solve the previously discussed problems of quantifying and comparing different people's happiness. Making use of surveys or similar means to obtain data is nothing but a specific procedure of aggregation that attaches a chosen weight to everybody's state of mind, making it possible to add the results together and arrive at a quantity for the whole nation. Intuitively, fairness seems to demand to assign the same weight to every citizen. But as we have seen in the previous section there is no scientific basis for this assignment. One might for example argue that a person's suffering from environmental distress depends on their exposure and such on their place of living, which should be reflected in the weighting of their (un-)happiness. Or consider it was shown that the genetic ancestry of the majority of one nation's citizens is responsible for a generally higher contempt with their social status. Should we not then take this into account when comparing the happiness of different nations? And if so, how?

We are thus back at the century-old problem of how to aggregate happiness.

\section{POSSIBILITY VERSUS UTILITY}

Considering the problems with aggregating happiness, we will here follow a different approach to address the question of societal well-being. We propose that the maximization of utilities is not the fundamental driving force, neither of the individual, nor of our combined social, political and economical systems, but that it is another quantity that is being optimized. The hypothesis is that what we work towards instead, both personally and collectively, is optimizing possibilities. This quantity constitutes an utility function, thus leaving the apparatus of microeconomics functional as usual, but this utility function has the merit that it can be aggregated, thus solving the previously discussed problems. We will further argue that possibilities provide a substitute for happiness that is at least in principle objectively quantifiable.

Let us start then with asking a simple question: Why do we work to get rich? Money itself is not of use, except possibly to paper the walls. As the saying goes, one cannot eat money. Money however promises safety, and it brings influence. It is not money itself that we desire, it is the possibilities it opens, whether we will eventually use them or not. What we aim to avoid is running out of possibilities, since lack of possibilities brings us in great risk of becoming victim of changing circumstances that we cannot adapt to. Without possibilities there is no change, without change there is no innovation, without innovation no progress. The whole power of capitalism stems from the allocation and investment of money to explore further possibilities. Heidegger described death as the possibility of impossibility of all possibilities $^{3}$, a phrase that seems equally apt also for bankruptcy.

This might serve as a motivation for why we will in the following consider maximizing possibilities as the driving force for the dynamics of our economies. It should be understood this is a hypothesis, but one that we hope becomes plausible and whose usefulness becomes apparent in the following. Eventually however, it would need to be tested by contrasting it with real world data. But first we need to lay out what the economy looks like. 
The economic system is described by a network with $N$ nodes of agents, exchanging $M$ goods. Agents, denoted $F_{\mathrm{A}}$, could be consumers or producers, households or companies. Goods are anything that can be exchanged between agents, including labor, money, services or information. Agents have each an inventory with entries $x_{\mathrm{A} a}(t)$, which is the amount of good $a$ agent $A$ has at time $t$ in some agreed upon basis of units. The set of basis vectors containing one item of a good span the space of goods $X$, its zero vector will be denoted $\mathbf{0}$ (goods that do not belong to anybody may be considered belonging to a dummy agent). We will neglect that goods might be perishable and thus strictly speaking should have a time dependence too, but this could easily be incorporated in the framework.

The links of the network are described by a tensor $E_{\mathrm{AB} a}(t)$, where capital indices label agents and run from 1 to $N$, and small indices label commodities and run from 1 to $M$. Then $E_{\mathrm{AB} a}(t)$ is the amount of good $a$ exchanged between agents $A$ and $B$ at time $t$. The entries can be positive or negative valued, depending on whether a good was obtained or given away, it is thus ${ }^{4} E_{\mathrm{AB} a}=-E_{\mathrm{AB} a}$. We will for convenience assume that exchanging goods happens instantaneously. The time parameter itself is not necessarily related to any real clock, but just what prevents everything from happening at once, as J. Wheeler put it. Time proceeds in discrete steps with step size $\Delta t$. An agent $F_{\mathrm{A}}$ with no links connected to it will have $E_{\mathrm{AB}}(t)=\mathbf{0}$ for each B. We will call it 'inactive' at time $t$. We will refer to a trade as being 'possible' if the agent can reach agreement on it with an exchange partner. With a slight abuse of word, the trades encoded in $E_{\mathrm{A}}$ do include non-exchange actions, such as giving a gift without return but, more importantly, connecting a good to a previously inactive node.

The network we are considering does not grow in the sense that $N$ and $M$ do not change with time. However, a good might not have been be produced or exchanged, or an agent might have been inactive before a time $t_{0}$. The network itself is not necessarily simply connected at any time. These quantities are schematically depicted in Figure 1.

The nodes of the network are the agents with action functions $F_{\mathrm{A}}$ that act on input at time $t$ to produce output at time $t+\Delta t$

$$
F_{\mathrm{A}}: \mathrm{X} \rightarrow \mathrm{X}, F_{\mathrm{A}}: x_{\mathrm{A}}^{i n}(t) \mapsto x_{\mathrm{A}}^{\text {out }}(t+\Delta t) .
$$

These functions will generally be non-linear. They contain all the details about the individual agent, in particular his memory, expectations and future plans and thus the conditions under which it will agree on transactions $E_{\mathrm{AB}}$. The actions of the agent encoded in this function will in general depend on what input he previously used (what goods consumed, what services used). The agent $F_{\mathrm{A}}$ might for example contain how well maintained a factory's machinery is,

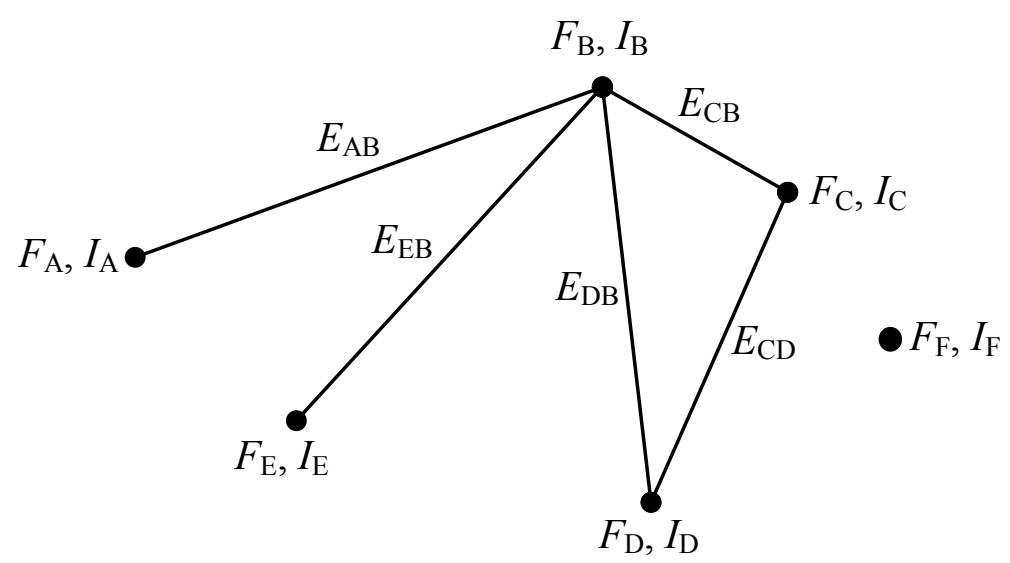

Figure 1. The state of the economy at a moment in time. Depicted are links with nonvanishing exchange matrices. The agent $F_{\mathrm{F}}$ is inactive. 
or what skills a worker has acquired over his lifetime. Any production process defines a 'netput' vector

$$
x_{\mathrm{A}}^{n p}(t) \equiv x_{\mathrm{A}}^{i n}(t)-F_{A}\left(x_{A}^{i n}, t+\Delta t\right) .
$$

We will refer to two production plans as being different if their netput vectors differ. The state of the economy at time $t$ is described by the set $S(t)=\left\{x_{\mathrm{A}}(t), E_{\mathrm{AB}}(t), W(t)\right\}$, where $W(t)$ contains all external conditions of the world that are not already described by the network, such as for example the weather, the geological environment, or the political system. It also contains all externalities that might influence the agent's actions but are not obtained by trade. The actions of agents in the network can be affected by and affect the external conditions. $F_{\mathrm{A}}(t)$ and $W(t)$ encode the dynamics of the system. While $W(t)$ should in principle be given by an evolution law, in practice it will only be known probabilistically. Quantity $F_{\mathrm{A}}(t)$ depends on the actions of the agent in each time step. We will use $S_{\mathrm{i}}$ to refer to a specific initial state at time $t_{\mathrm{i}}$.

The agent's inventory updates according to

$$
x_{A}(t+\Delta t) \equiv \sum_{B} E_{A B}(t)+F_{A}\left[x_{A}(t), t\right] .
$$

saying that the inventory at time $t+\Delta t$ is what was produced from the inventory at time $t$ plus goods obtained from trade. At each time step the agents decide what to do with their inventory. The actions they can perform is producing output from input and/or connecting inventory to other nodes. They can connect to inactive nodes, which describes the creation of a new process (or at least the attempt to do so). Agents do not necessarily have to use all of their inventory at one time step.

We can now define what we mean with the notion of possibilities. The total number of possibilities of the network $P[S(t)]$ at one time moment is the number of different actions the economy's agents could take. More important than the possibilities at one moment in time is the number of possible actions over a period of time. Since an agent's actions affect that and others' agents inventory and the state of the economy, the possibilities at later times will depend on the previous choices. Each time-ordered series of possible actions defines a history of the economy $H\left(S_{\mathrm{i}}, t_{\mathrm{e}}\right)$. Each different action of any agent defines a branching of the paths of the state of the economy. The total number of possible paths from $S_{\mathrm{i}}$ to a final time $t_{\mathrm{e}}$ we will denote $\# H\left(S_{\mathrm{i}}, t_{\mathrm{e}}\right)$. It will in general depend on the external conditions $W(t)$. Figure 2 depicts a tree of such states.

Let us state the following hypothesis:

Hypothesis: Given an initial state $S_{\mathrm{i}}$ and an endtime $t_{\mathrm{e}}$ the economic system maximizes $\# H\left(S_{\mathrm{i}}, t_{\mathrm{e}}\right)$.

The endtime $t_{\mathrm{e}}$ could theoretically be infinite, but more realistically would be the time when our economic system is no longer adequately described by the here proposed framework, either because of significant changes of the human species, our social systems, the environment, or a combination of those. While this is philosophically a troublesome time to set, we will see in the following that for practical purposes we need not fix this unknown time anyway. In case $\# H$ was infinite, one further would have to deal with ratios of the number of paths which would be an added complication but theoretically doable. However, this too will turn out not to be necessary in practice.

Maximization with a given initial condition does not necessarily mean an increase of possibilities with time. The initial conditions could result in a breakdown of the system with any possible course of action, such that even the optimal history results in a decrease of possibilities. Note further that the quantity defined here does not leave interpretational 


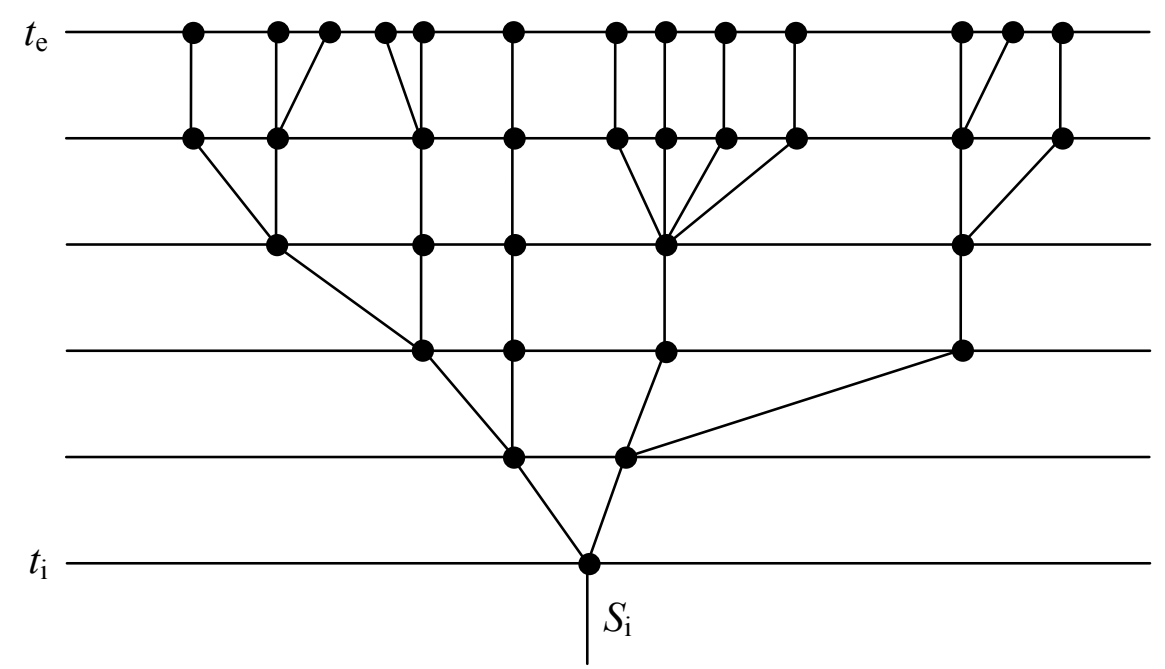

Figure 2. Every path from $t_{\mathrm{i}}$ to $t_{\mathrm{e}}$ is a possible evolution of the state of the economy $S$. Dots in this diagram correspond to states of the network as depicted in Figure 1.

questions open. It is not the possibilities for a particular purpose that are being counted, but just all possibilities.

That is as far as the evolution of the system is concerned. One should understand this in a similar sense to the working of natural selection that optimizes the survival chances of genes. While this might be the underlying trend of Nature as a whole, looking at the behavior of an individual organism over a short period of time, an organism might do better or worse in reaching this goal. Consequently, the selective process in the whole system might proceed faster or not so fast, and at any time we will be faced with some variety of species that perform differently. Thus we have to ask now how the individual behavior supports this maximization of possible histories.

For this purpose we define an agent's possibilities in a state of the economy $P_{\mathrm{A}}[S(t)]$ as the number of all possible actions that the agent could take with his inventory at this time. For example if the agent has 3 apples, 2 empty bottles and 5 bananas, he could trade 1 to 3 apples, 1 or 2 bottles, and/or 1 to 5 bananas with whoever is willing to trade them. Or he could consume some apples or bananas, or make juice of some of the apples (both of which would be a production process), or any combination of this. Then the space of possible actions is

$$
\mathrm{A}_{A}(t) \equiv\left\{\left(x_{A}^{e}(t), x_{A}^{i n}(t)\right) \mid x_{A}^{e}(t)+x_{A}^{i n}(t) \leq x_{A}(t)\right\},
$$

where $x_{A}^{e}$ is a possible trade for agent $F_{\mathrm{A}}, x_{A}^{\text {in }}$ is the input of a possible production process, and the inequality is as usual meant to hold for every entry of the vector. This space is degenerate since not all of the production processes might differ in their netput vector. Once could e.g. add input that is not used in a process altogether, but this should not count as an additional possibility. Thus we formally mod out these options over the set of netput vectors $A_{\mathrm{A}} /\left\{x_{A}^{n p}\right\}$, meaning we only count two elements of $A_{\mathrm{A}}$ as different possibilities if their netput vector differs.

The number of possible actions of the agent is then the cardinality of that space $P_{\mathrm{A}}[S(t)]=\# A_{\mathrm{A}} /\left\{x_{A}^{n p}\right\}$.

Note that according to our definition of the exchange matrices, this space contains the actions of connecting goods to a previously inactive node. That would correspond e.g. to the agent of 
putting his bananas on a pile and hoping for somebody to bring milk and a mixer. As before we then see that the number of possibilities at one time is not a particularly insightful quantity. This space is vast, but a lot of the possible actions will significantly decrease future possibilities (the bananas may just rot away). More relevant is thus the number of possible future evolutions an action opens. We define the space of all possible time-ordered sequences of actions from an initial state to an endtime to be $H_{\mathrm{A}}\left(S_{\mathrm{i}}, t_{\mathrm{e}}\right)$. The number of possible paths is then $\# H_{\mathrm{A}}\left(S_{\mathrm{i}}, t_{\mathrm{e}}\right)$.

An agent's possibilities depend on his inventory, but they do also depend on the network architecture and his location in it, and thus eventually also on the actions of the other agents. This, too, is similar to natural selection - the agent's performance depends on the environment that is also used and shaped by others. This then adds an additional uncertainty to his optimization problem. If he assumes all other agents decide their actions using the same model as he does, their behavior is not uncertain, but in general this lack of knowledge about the other's behavior does enter the estimate of probabilities for different paths. What each agent individually tries to achieve is a maximization of future possibilities. While this would be an exact prescription if the evolution of the state of the world and the model agents use to make decisions was known, in lack of this knowledge only probabilities for possibilities can be given. Into the optimization then enters the agent's willingness to take risk.

Before discussing the consequences of this setting, let us note that the number of possible paths (of an agent or of the economy itself) will grow in time just because choosing from a fixed set options in each moment already allows for many different histories. If there are $n$ different choices, and this number remains constant over time, the number of possible paths will grow with $n^{\left(t_{e}-t_{i}\right) / \Delta t}$. A more useful quantity to characterize the growth of possibilities is thus the natural logarithm of the number of histories $Q(t):=\ln P[S(t)]$, or for the single agent $Q_{\mathrm{A}}(t):=\ln P_{\mathrm{A}}[S(t)]$. If the time derivative of these quantities vanishes, the set of options remains constant.

Another important point is that an agent tries to maximize possible paths of actions for a particular time period $T_{\mathrm{A}}$. This time period might be individually different and might or might not exceed the agent's own lifetime. If it is a sharp cutoff, it corresponds to the "Buxton Index" [7]. More generally, if the agent instead considers short-term maximization more relevant than longterm maximization he would discount the future in the usual way. Though $T_{\mathrm{A}}$ theoretically could be infinitely long, humans do not usually make plans for eternity. It is for this reason that the endtime $t_{\mathrm{e}}$ is practically irrelevant since one would not expect it to enter any human considerations.

In their optimization process, agents are subject to biological, physiological, psychological and cognitive constraints. The first three represent constraints on what an agent can or will agree to do, while the latter is a constraint on how well he can plan and judge.

As far as the first three constraints are concerned, for example the survival of an agent is a prerequisite for her further action and thus a top priority, and she will have to balance leisure-time with work time to remain resilient and functional over a maximal time period. Agents might further have a limited ability to adapt to changing conditions which constrains their courses of actions and might result in self-limiting their actions to histories that evolve slow enough to accommodate their needs ${ }^{5}$. These constraints are encoded in the agent's functions $F_{\mathrm{A}}$, and with them taken into account the outcome of the optimization might be lowered. The constraints might be expressed in the form that if $\# H_{\mathrm{A}}$ increases rapidly, or if there are substantial changes to the network structure, the productivity of the agent decreases.

Given these constraints on what the agent can and will do, it is thus not surprising possibilities are positively correlated with happiness, since well-being is in many cases 
beneficial for productivity and creativity. The difference between optimizing either would become apparent if it could be shown people sometimes chose to increase their possibilities rather than increasing their happiness. While in a slowly changing environment (slow in comparison to effects of natural selection to become relevant, i.e. at least some generations), both should be well aligned with each other, in a fast changing environment happiness might be optimal for choices that do no longer optimize possibilities since biological adaption has not caught $u^{6}$. Agents also have finite cognitive abilities, meaning they will not be able to accurately evaluate and judge all possibilities they have and thus will make mistakes. An agent that performs very badly, e.g. by choosing an action that drastically limits his future possibilities runs in great risk of becoming inactive, and in any case reduces his potential to influence the course of the economy. This is just because it is exactly those with few possibilities who have few impact on future change. The economy will thus come to be dominated by agents that perform well in optimizing their possibilities ${ }^{7}$.

The number of an agent's possibilities for taking a particular action represents a utility function of that agent. As we noted earlier, for micro-economics it is irrelevant exactly what the function to be optimized describes. In contrast to the usual case however, the number of possibilities is an absolute number that also allows for intra- and interpersonal comparisons.

Let us then discuss how the individual level connects to the collective level.

\section{WELFARE ECONOMICS}

Merely looking at individual actions, the total number of possibilities for the whole economic system is not automatically maximized. Consider for example a network structure describing a free market. In this situation, we know that the individual actions will work towards Pareto efficiency. The number of possibilities however is an aggregated measure not taken into account in this efficiency. There could thus be trades that do decrease the possibilities of some agents, but do increase the possibilities of a larger group of agents, leading to an overall increase.

At this point it becomes relevant that our economic systems are always complemented by social and political systems. The social and political context is commonly treated as external to the economic system, providing rules, regulations and norms, which we previously encoded in the function $W(t)$. However, we should actually be interested in the combined dynamics of the whole, since social values, politics and economics have a non-negligible interaction and neither of them can strictly speaking be considered independently. Their separation is an additional assumption that will not in general be fulfilled. Then, for the question of collective optimization, the optimization should be one of all these systems combined. In this case, the function $W(t)$, that we previously considered as externally given, is a function of the variables of the economy, and the central hypothesis is that in this case the optimization includes $W(t)$. Treating the political and social environment as external is however often justified since one might argue that the political process operates more slowly than that of the economy and social norms and values change even more slowly. The question of social welfare we want to address in this section then concerns the combination of political environment and the economy.

The central hypothesis offered here is, again, that we work towards maximizing our total possibilities. Pareto efficiency alone is then not necessarily optimal and thus our economic systems are not entirely free markets but complemented by laws, regulations, and taxes supposed to complete the task of optimization the economy does not already fulfill. This then provides a rationale for many governmental public services that lack a justification if one believes in the free market paradigm: a good education opens future possibilities; retirement options ensure we do not run out of possibilities when we age; social and health insurance are 
supposed to lower the risk of early death. Even the political system itself can be more or less helpful to this end of optimizing possibilities. Democracy is based on personal freedom, and providing a social and political environment supportive of upwards mobility is the essence of maximizing everybody's possibilities.

Human beings further naturally have an interest in ensuring the survival of their offspring. Many of us work hard to make the world a better place for future generations. The relevance of improving our lives and the lives of those to come is a motivation for constant innovation and improvement, and not spoiling the possibilities of future generations is what underlies the environmental movement, captured in the proverb "We do not inherit the Earth from our parents, we borrow it from our children," reminding us of our responsibilities.

Environmental protection is often origin of heated argumentation because we frequently use for our present well-being resources that might no longer be available in the future. Employing the utility function we would wonder how much more important our happiness now is compared to that of coming generations. As previously discussed, even neglecting our limited ability to predict the future, such a comparison is impossible since different agent's happiness stand in no absolute relation to each other. Similarly, whether or not people were less happy some centuries ago because their lives were on the average shorter and offered fewer possibilities is a question we will probably never be able to answer.

But with the above outlined framework we can now rephrase this discussion. Does voluntarily reducing growth now and thus giving up possible histories in the short-term, or causing a reduction of possibilities in the future and giving up branches in the long-term, amounts eventually, with some probability, to more or less total possibilities? And while this reformulation still contains the problem of estimating the evolution of the system and is challenged by the inaccuracy of our predictions, it does no longer entail the necessity of comparing agent's ordinal utilities.

The case is similar with uneven distributions of wealth displaying a gap between rich and the poor. While a comparison between a rich man's and a poor man's utility for $\$ 5000$ cannot be done, the increase or decrease of future possibilities opened with this check can be compared. Providing a family in a developing country with basic immunizations and a mosquito net can vastly increase their future possibilities, while giving up the amount of money needed for this in a developed country might hardly decrease the number of possibilities.

As before when comparing the now with the then, this comparison between the here and the there does still depend on our ability to estimate future evolution, but it got rid of the problem with relating different peoples' utilities. Of course the question what action increases the total number of possibilities is infinitely more involved than the brief examples above. Redistributing wealth causes disincentives for work, which might eventually reduce possibilities even further. There also remain the questions of value, for example what amount of reducing somebody's possibilities to increase the total possibilities is considered fair, as a redistribution considered unfair may lead to political frustration and eventually also decrease rather than increase possibilities. The point here is not to make any claims what particular action is beneficial for social welfare, but that the quantification of possibilities is a useful tool to characterize the impact of planned actions. How many possibilities is one country willing to give up to increase the possibilities of another country? How much risk should we export on future generations? These are questions that only political process can decide. What we can do however is to provide a measure for the impact of such decisions. 


\section{DISCUSSION AND SUMMARRY}

We have here proposed that individuals strive to optimize the number of future possibilities and that our political systems are tools to collectively improve on the total number of possibilities of a group or nation. Of course these tools are imperfect. Like individual human action, the realized political environment can work better or worse towards the maximization of total possibilities since we might be lacking information, understanding, or just make wrong decisions. Much like the efficiency of our economic system has benefitted from a (partial) theoretical understanding of its models, the function of our combined economical and political system might benefit from understanding the here proposed model.

It is however not necessary to believe the hypothesis proposed here to find the number of possibilities a useful quantity: The number of possibilities provides a substitute for the ethereal notion of 'happiness' and thus makes a scientifically sound aggregation possible. While we have here not constructed explicit examples, it is in principle a quantifiable measure. For practical purposes, one would of course have to make simplifying assumptions.

Consider one would like to quantify the possibilities of two families in two different nations for comparison. First, one would chose a suitable time-step, say, one month, and a suitable time period over which to trace histories, say, four years. Then, one would have to agree on what aspects of life to consider - access to goods, education, public and private services, health care, etc - and itemize them or assign to them suitable amounts, each constituting a possible, discrete, choice. In addition, one might consider a number of representative contingencies of interest that might happen with some probability, for example a dry summer or illness of a family member. After this, one could compute what possible combinations of choices the person can make with their monthly income. Lacking health care for example might mean for a family with a sick child that their possibilities are drastically reduced. Lacking access to transportation might reduce the access to education or medical help, both resulting in a lowered number of future possibilities. The selection of goods reflects the general infrastructure and status of the economy, while the job opportunities affect the families' possibilities through the monthly available money to spend.

Of course the so constructed measure would only be an approximate indicator of the 'true' number of possibilities and depend on the selection of histories considered, but with suitable choices it could provide a good impression of a nation's well-being.

One can devise tests for the here proposed hypothesis along the same lines. To that end, one needs to study situations where people, besides engaging in economic exchange, have collective decision making processes that supplement the free market mechanism. While most democracies are of that sort, for practical purposes a smaller system would be preferable. A real-life example may be agricultural communities in developing countries, or possibly some game can be devised which simulates a suitable setup. One then needs again a quantification and discretization of possibilities as outlined in the previous paragraph. The question to test is whether people collectively strive to a situation where, given sufficient information, the aggregated number of possibilities for all of them is maximized.

In summary, we have proposed here that the dynamics of our combined economic and political systems work towards optimizing the number of possibilities. Considering only the economy, the number of possibilities constitutes a cardinal utility function that allows intraand interpersonal comparison, and thus makes aggregation possible. This aggregation results in an additional measure whose optimization cannot be achieved within the economy alone, thus providing a rationale for politically pursued social welfare. We have further outlined 
how the number of possibilities can in practice be calculated by selecting representative goods, public and private services, as well as contingencies. In this manner, it may provide a measure supplementary to the GDP.

\section{ACKNOWLEDGMENTS}

I thank Arun Gupta, Kelly John Rose, Stefan Scherer, Lee Smolin and Samuel Vasquez for helpful discussions.

\section{REMARKS}

${ }^{1}$ http://www.happyplanetindex.org.

${ }^{2}$ http://www.stiglitz-sen-fitoussi.fr/en.

${ }^{3}$ Die Möglichkeit der Unmöglichkeit aller Möglichkeiten.

${ }^{4}$ In an economy with fiat money, most of the exchange will happen via one particular good that counts this money. While the exchange matrix then will remain mostly empty, this case is also covered by the outlined framework.

${ }^{5}$ Irvin Yalom lists 'freedom' as one of the four existential fears, since being faced with too many choices can greatly increase the anxiety to make irreversible mistakes. Some religious sects refuse making use of medical or technological achievements of our modern civilizations (one might say though with the attempt to increase possibilities in afterlife). These are only two examples of how psychological constraints might result in self-limiting ones possibilities.

${ }^{6} \mathrm{~A}$ large number of people in the Western world nowadays suffers from permanent stress in reaction to the demands of their every-day life. This biological stress reaction is arguably a relic of evolution that is in most cases no longer beneficial in the modern world. One may ponder the question then if not the holding-on to a stressful lifestyle is an expression of optimizing possibilities rather than happiness.

${ }^{7}$ At least over their own lifetime. Increasing one's lifespan or immortality could result in a dramatic increase of individual possibilities. It is thus unsurprisingly a goal that is vigorously pursued.

\section{REFERENCES}

[1] Pareto, V.: Manual of Political Economy. In Italian.

M. Kelley Publishers, 1971,

[2] Van Praag, B.M.S.: Ordinal and Cardinal Utility: An Integration of the Two Dimensions of the Welfare Concept.

Journal of Econometrics 50(1-2), 69-89, 1991, http://dx.doi.org/10.1016/0304-4076(91)90090-Z,

[3] Ng, Y.-K.: A Case for Happiness, Cardinalism, and Interpersonal Comparability. Economic Journal 107(445), 1848-1858, 1997, http://dx.doi.org/10.1111/j.1468-0297.1997.tb00087.x,

[4] Kornienko, T.: A Cognitive Basis for Cardinal Utility. https://docs.google.com/file/d/0B8TX9abA2uy0ZjNFR2V1eWFndXc/edit?pli=1, accessed 3 October 2010,

[5] Goossens, Y. et al.: Alternative progress indicators to Gross Domestic Product (GDP) as a means towards sustainable development.

Study IP/A/ENVI/ST/2007-10, European Parliament, 2007, http://www.beyond-gdp.eu/download/bgdp-bp-goossens.pdf, accessed 6 July 2009,

[6] Castle, T.: U.K. to measure happiness alongside GDP.

Globe and Mail, 25 November 2010,

[7] Dijkstra, E.W.: Selected Writings on Computing: A Personal Perspective.

Springer-Verlag, New York, 1982,

http://dx.doi.org/10.1007/978-1-4612-5695-3. 


\section{O PROBLEMU MJERENJA SREĆE}

Sabine Hossenfelder

NORDITA

Štokholm, Švedska

\section{SAŽETAK}

Pitanje kako mjeriti i prikupljati sreću starije je od stoljeća. Zadnjih godina njegovo je značenje poraslo zbog težnji da se BDP zamijeni indeksom koji bi bolje indicirao blagostanje, iako su takve težnje povezane $s$ ozbiljnim konceptualnim problemima. Nakon kraćeg navođenja tih problema predlaže se da im se pristupi, umjesto uobičajenom ordinalnom korisnošću, alternativnom veličinom koja je maksimizirana u ekonomskim transakcijama. Ta veličina broji buduće mogućnosti koje se otvaraju zahvaljujući robi. Velika prednost ovog pristupa je to što je, u principu, broj mogućnosti objektivna mjera koja omogućuje individualnu usporedbu ili usporedbe više osoba. Postavljen je okvir modela i prodiskutirano njegovo značenje za društveno blagostanje. U radu nije izravno izračunata mjera kojom bi se zamijenio BDP nego je naznačeno kako bi se to provelo.

\section{KLJUČNE RIJEČI}

funkcija blagostanja, alternativa za BDP 